\title{
KARAKTERISTIK MUTU PELAYANAN PROSES PEMBELAJARAN DI PROGRAM STUDI BIOLOGI FMIPA UNSRAT PADA SEMESTER GENAP 2017/2018 MENGGUNAKAN ANALISIS BIPLOT
}

\author{
Aron Fedri Pualalo ${ }^{1)}$, Altien Rindengan ${ }^{1)}$, Djoni Hatidja ${ }^{1 *}$ \\ ${ }^{1)}$ Program Studi Matematika, Fakultas Matematika dan Ilmu Pengetahuan Alam, \\ Universitas Sam Ratulangi Manado \\ ${ }^{*}$ Corresponding Author: e-mail: dhatidja@gmail.com
}

\begin{abstract}
ABSTRAK
Tujuan penelitian ini adalah mengetahui karakteristik kinerja dosen dalam proses belajar mengajar berdasarkan faktor penentu mutu pelayanan di Program Studi Biologi FMIPA UNSRAT menggunakan analisis biplot. Data yang digunakan dalam penelitian ini adalah data primer yang diperoleh dari mahasiswa Program Studi Biologi pada semester genap 2017/2018. Pengambilan data dilakukan dengan menggunakan Purposive Sampling pada seluruh mata kuliah dan Simple Random Sampling pada mahasiswa yang mengambil mata kuliah tersebut dan selanjutnya diwawancarai dalam bentuk pengisian kuisioner penilaian terhadap kinerja dosen dalam proses pembelajaran. Hasilnya menunjukkan bahwa dosen-dosen yang dikategorikan memiliki karakteristik mutu pelayanan yang relatif sama adalah 1). DS28, DS15, DS11, DS25, DS12, DS18, DS16; 2). DS14 dan DS27; 3). DS2 dan DS23; 4). DS4 dan DS22; 5). DS26, DS30, DS31, DS13, DS8, DS7, DS6; 6). DS24, DS17 dan DS1.
\end{abstract}

Kata kunci: Analisis Biplot, Karakteristik Mutu Pelayanan, FMIPA UNSRAT

\section{THE CHARACTERISTICS OF SERVICE QUALITY OF THE LEARNING PROCESS IN BIOLOGY DEPARTEMENT OF FMIPA UNSRAT ON EVEN- SEMESTER 2017/2018 USING BIPLOT ANALYSIS}

\begin{abstract}
The objctive of this research was determine the characteristics of lecturers in teaching and learning process, based on the factors using Biplot Analysis. The primary data used in this research are obtained from Biology students on even-semester 2017/201, data retrieving using purposive samping to all courses and using simple random sampling on students who took the course. The results showed that lecturers who categorized as having relatively similar service quality characteristics, are 1). DS28, DS15, DS11, DS25, DS12, DS18, DS16; 2). DS14 and DS27; 3). DS2 and DS23; 4). DS4 and DS22; 5). DS26, DS30, DS31, DS13, DS8, DS7, DS6; 6). DS24, DS17 and DS1.
\end{abstract}

Keywords: Biplot Analysis, The Characteristics of Service Quality, FMIPA UNSRAT

Article History:

Received: July 4, 2019

Accepted: July 15, 2019

Published: July 15, 2019

\section{PENDAHULUAN}

Pelayanan adalah kunci keberhasilan dalam berbagai usaha atau kegiatan yang bersifat jasa (Moenir, 2008). Perguruan tinggi merupakan salah satu lembaga yang bergerak dalam jasa pelayanan pendidikan. Tenaga pendidik dalam hal ini dosen, merupakan bagian dari pengolah jasa pendidikan yang memiliki karakteristik tertentu, baik secara langsung maupun tidak langsung yang dalam kinerjanya dijadikan sebagai bahan penilaian dasar oleh mahasiswa.

Fakultas Matematika dan Ilmu Pengetahuan Alam Universitas Sam Ratulangi (FMIPA UNSRAT) khususnya PS 
Biologi merupakan lembaga pendidikan yang menyediakan layanan jasa pendidikan bagi mahasiswa. Dalam melaksanakan tugas dan kerjanya, Program Studi Biologi FMIPA UNSRAT dituntut untuk menjadi profesional bukan hanya pada jasa yang berbentuk fisik melainkan pelayanan penuh kepada mahasiswa agar terciptanya kualitas pelayanan pendidikan yang kompeten oleh para tenaga pendidik dengan bidangnya masing-masing

Pengukuran kinerja dosen dilakukan berdasarkan penilaian mahasiswa terhadap faktor-faktor penentu mutu pelayanan dalam proses pembelajaran. Semakin banyak peubah yang akan dinilai, maka perlu dilihat peubah apa saja yang harus diperhatikan dalam proses belajar mengajar sehingga dapat dijadikan bahan evaluasi diri untuk meningkatkan kinerja PS Biologi FMIPA UNSRAT yang lebih baik, efektif dan efisien.

Analisis biplot merupakan salah satu bagian dari analisis peubah ganda yang dapat menyajikan secara simultan dalam bentuk gambar dua dimensi antara faktor penentu mutu pelayanan (sebagai peubah) dengan mata kuliah (sebagai objek).

Tumilaar, et al., (2014); Pangemanan, et al., (2014), Liputo, et al., (2014), telah melaksanakan penelitian mengenai karakteristik kinerja dosen Program Studi Matematika dalam proses pembelajaran serta persepsi alumni Program Studi Matematika terhadap kurikulum dan proses pembelajaran menggunakan analisis korespondensi. Penelitian saat ini lebih difokuskan pada penilaian mahasiswa terhadap proses pembelajaran.

Purwanto, et al., (2015), telah melaksanakan penelitian tentang pemetaan SMA/SMK di Kabupaten Minahasa Tenggara Berdasarkan Empat Indikator Standar Nasional Pendidikan dengan menggunakan analisis biplot. Gobel, et al., (2013), juga telah melakukan penelitian sebelumnya tentang analisis biplot terhadap karakteristik kualitas pengajar berdasarkan faktor mutu pelayanan, namun objek yang digunakan adalah Jurusan Matematika FMIPA UNSRAT dengan data pada semester genap 2011/2012.

Berdasarkan hal-hal tersebut, maka pada penelitian ini akan dilakukan analisis terhadap mutu pelayanan dari segi kinerja dosen pada proses pembelajaran di PS Biologi FMIPA UNSRAT pada Semester Genap 2017/2018 dengan menggunakan analisis biplot.

\section{Mutu Pendidikan}

Mutu pendidikan merupakan faktor yang sangat penting dalam meningkatkan kualitas sumber daya manusia. Mutu pendidikan telah diatur dalam Peraturan Pemerintah (PP) nomor 19 tahun 2005 tentang Standar Nasional Pendidikan. Ruang lingkup Standar Nasional pendidikan adalah standar kompetensi lulusan, standar isi, standar sarana dan prasarana, standar proses, standar pendidikan dan tenaga pendidikan, standar pengelolaan, standar pembiayaan pendidikan dan standar penilaian pendidikan.

\section{Mutu Pelayanan}

Lima (5) faktor yang menentukan mutu pelayanan Kotler (2000), yaitu:

1. Tangible (bukti langsung) mencakup fasilitas fisik, perlengkapan, pegawai dan sarana komunikasi.

2. Reliability (kehandalan) yaitu kemampuan memberikan pelayanan yang dijanjikan dengan segera, akurat, dan memuaskan.

3. Responsiveness (daya tanggap) yaitu keinginan staf membantu para pelanggan dan memberikan layanan dengan tanggap.

4. Assurance (jaminan) mencakup pengetahuan, kompetensi, kesopanan dan sifat dapat dipercaya yang dimiliki staf.

5. Empathy (empati) meliputi kemudahan dalam menjalin relasi, komunikasi yang baik, perhatian pribadi, dan pemahaman atas kebutuhan individu para pelanggan.

\section{Analisis Biplot}

Biplot adalah gambaran dua dimensi pada suatu matriks data $X$ yang menunjukkan suatu titik untuk setiap $n$ vektor pengamatan (baris $X$ ) dengan suatu titik untuk setiap $p$ peubah $($ kolom $X)$. Biplot diperkenalkan oleh Gabriel tahun 1971 yang mengembangkan metode biplot sebagai suatu alat analisis data yang dapat meringkas informasi dari suatu matriks data yang besar, dan telah diperbaharui oleh Gower and Hand pada tahun 1996 (Rencher, 2002).

Empat hal penting yang dapat dilihat pada biplot adalah : 
1. Hubungan (korelasi) antar peubah, dengan menggunakan biplot peubah akan digambarkan sebagai garis berarah. Dua peubah yang memiliki korelasi positif tinggi akan digambarkan sebagai dua buah garis dengan arah yang sama, atau membentuk sudut yang sempit. Apabila dua peubah yang memiliki korelasi negatif tinggi akan digambarkan dalam bentuk dua garis yang arahnya berlawanan, atau membentuk sudut yang lebar (tumpul). Sedangkan dua buah peubah yang tidak berkorelasi akan digambarkan dalam bentuk dua garis yang mendekati $90^{\circ}$ (siku-siku).

2. Keragaman peubah, informasi ini digunakan untuk melihat apakah ada peubah tertentu yang nilainya hampir sama setiap objek ada yang sama besar dan ada juga yang sangat kecil. Dengan informasi ini, bisa diperkirakan pada peubah mana strategi tertentu harus ditingkatkan, serta sebaliknya. Dalam biplot, peubah dengan keragaman kecil digambarkan dengan vektor yang pendek, sedangkan peubah yang ragamnya besar digambarkan sebagai vektor yang panjang.

3. Kedekatan antar objek, informasi ini bisa dijadikan panduan objek mana yang memiliki kemiripan karakteristik dengan objek tertentu. Dalam biplot, dua objek dengan karakteristik sama akan digambarkan sebagai dua titik yang posisinya berdekatan.

4. Nilai peubah pada suatu objek, informasi ini digunakan untuk melihat keunggulan dari setiap objek. Objek yang terletak searah dengan arah dari suatu peubah dikatakan bahwa pada objek tersebut nilainya diatas rata-rata. Sebaliknya jika objek lain terletak berlawanan dengan arah dari peubah tersebut maka objek tersebut memiliki nilai dekat dengan ratarata (Mattjik et al., 2004).

Analisis biplot didasarkan pada penguraian nilai singular suatu matriks (Singular Value Decompotion, SVD). Misalkan suatu matriks data $X$ yang memiliki rank $r$ berukuran $\left(\begin{array}{lll}n & \mathrm{x} & p\end{array}\right)$ yang berisi $n$ pengamatan dan $p$ peubah, maka matriks tersebut dapat dituliskan menjadi:

$$
X=U L A^{\prime}
$$

dengan $U$ dan $A$ masing-masing matriks berukuran $(n \times r)$ dan $(p \times r)$ Sehingga
$U^{\prime} U=A^{\prime} A=I_{r}$. Jika $\lambda_{i}$ adalah akar ciri ke$i$ dari matriks $X^{\prime} X$, maka $L$ adalah matriks diagonal berukuran $\left(\begin{array}{lll}r & x & r\end{array}\right)$ dengan unsurunsur diagonal adalah akar kuadrat dari akar ciri $X^{\prime} X$ sehingga $\sqrt{\lambda_{1}} \geq \sqrt{\lambda_{2}} \geq \cdots \geq \sqrt{\lambda_{r}}$. Unsur-unsur diagonal dari matriks $L$ disebut nilai matriks singular matriks $X$. Kolomkolom matriks $U$ terdiri dari $r$ vektor ciri dari matriks $X^{\prime} X$. Kolom-kolom matriks $U$ disebut vektor singular kolom matriks $X$ dalam ruang berdimensi $n$. Kolom-kolom matriks $A$ terdiri dari $r$ vektor ciri dari matriks $X^{\prime} X$ yang berpadanan dengan akar ciri $\lambda$. Kolom-kolom matriks $A$ disebut vektor singular baris matriks $X$ dalam ruang berdimensi $p$. Adapun penjabaran persamaannya adalah:

$$
X=U L A^{\prime}=U L^{\alpha} L^{1-\alpha} A^{\prime}
$$

Menurut Jollife (1986) dengan memisah $G=U L^{\alpha}$ dan $H^{\prime}=L^{1-\alpha} A^{\prime}$, maka persamaan (2) dapat dituliskan sebagai:

$$
\begin{aligned}
X & =G_{(n \times r)} H_{(r x p)}^{\prime} \\
\text { dengan } & \\
G & =\left(g_{1}, \ldots, g_{n}\right)^{\prime} \\
H^{\prime} & =\left(h_{1}, \ldots, h_{n}\right)^{\prime}
\end{aligned}
$$

Maka unsur ke-(ij) matriks $X$ dapat ditulis sebagai

$$
\begin{gathered}
X_{i j}=g_{i} h_{j}, \\
i=1,2,3, \ldots, n ; j=1,2,3, \ldots, p .
\end{gathered}
$$

dimana,

$$
\begin{aligned}
g_{i}= & \text { Objek ke }-i \text { dari } X \\
h_{j}= & \text { Kolom ke- } j \text { dari } X \\
& (\text { Peubah ke- } j \text { ) }
\end{aligned}
$$

Jika $X$ berpangkat dua, maka vektor baris $g_{i}$ dan vektor kolom $h_{j}$ dapat digambarkan dalam ruang berdimensi dua. Sedangkan matriks $X$ yang berpangkat lebih dari dua yang dapat didekati dengan matriks berpangkat dua, sehingga persamaan (4) dapat ditulis menjadi

$$
X^{2}{ }_{i j}=g_{i} * h_{j} *
$$

dengan masing-masing $g_{i}{ }^{*}$ dan $h_{j}{ }^{*}$ mengandung 2 unsur pertama vektor $g_{\mathrm{i}}$ dan $h_{j}$.

Nilai $\alpha$ yang digunakan bersifat sembarang pada interval $0 \leq \alpha \leq 1$. Pengambilan nilai ekstrim $\alpha=0$ dan $\alpha=1$ akan berguna untuk mempermudah interpretasi hasil biplot (Jolliffe, 1986). Jika $\alpha=0$ maka $G=U$ dan $H=A L$, sehingga diperoleh persamaan :

$$
\begin{aligned}
X^{\prime} X & \left.=\left(G H^{\prime}\right)\right)^{\prime}\left(G H^{\prime}\right) \\
& =H G^{\prime} G H^{\prime} \\
& =H U^{\prime} U H^{\prime} \\
& =H H^{\prime}
\end{aligned}
$$


karena $X^{\prime} X=H H^{\prime}=(n-1) S(S$ adalah matriks peragam dari matriks $\mathrm{X}$ ), maka hasil kali $h_{j}{ }^{\prime}$ $h_{k}$ akan sama dengan $(n-1)$ kali peragam $S_{j k .}$ Oleh sebab itu, korelasi peubah ke-j dan peubah ke- $k$ ditunjukkan oleh kosinus antara vektor $h_{j}$ dan $h_{k}$.

Jika $\alpha=1$ maka $G=U L$ dan $H=A$, sehingga diperoleh :

$$
\begin{aligned}
X^{\prime} X & =\left(G H^{\prime}\right)\left(G H^{\prime}\right)^{\prime} \\
& =G H^{\prime} H G^{\prime} \\
& =G A^{\prime} A G^{\prime} \\
& =G G^{\prime}
\end{aligned}
$$

Tingkat keakuratan dari biplot dalam menerangkan tingkat keragaman dari matriks data asal dirumuskan sebagai berikut (Everit, 1978)

$$
\rho=\frac{\left(\lambda_{1}+\lambda_{2}\right)}{\sum_{k=1}^{p} \lambda_{k}}
$$

dimana, $\lambda_{1}=$ akar ciri terbesar pertama

$\lambda_{2}=$ akar ciri terbesar kedua

$\rho=$ tingkat keakuratan

Jika $\rho$ semakin mendekati nilai satu maka biplot yang diperoleh dari matriks pendekatan berpangkat dua akan memberikan penyajian yang semakin baik mengenai informasi-informasi yang terdapat pada data sebenarnya.

\section{METODOLOGI PENELITIAN}

\section{Waktu dan Tempat Penelitian}

Penelitian ini dilakukan di PS Biologi FMIPA UNSRAT, dimulai dari pengambilan data dalam bentuk kuesioner pada bulan Mei 2018 sampai bulan Juni 2018. Selanjutnya data diolah di Laboratorium Statistika Jurusan Matematika FMIPA UNSRAT.

\section{Data}

Data yang digunakan dalam penelitian adalah data primer yakni data yang diperoleh langsung dari sumber penelitian dengan menggunakan kuesioner dengan skala interval 0-10. Data primer diambil pada mahasiswa PS Biologi FMIPA UNSRAT yang sedang mengikuti mata kuliah pada semester genap 2017/2018.

\section{Populasi dan Sampel}

Populasi dalam penelitian ini adalah mahasiswa PS Biologi FMIPA UNSRAT yang mengambil mata kuliah pada semester genap 2017/2018. Penilaian terhadap kinerja dosen dalam proses perkuliahan dilakukan oleh mahasiswa melalui mata kuliah yang diajarkan oleh dosen.

Prosedur pengambilan data dilakukan sebagai berikut :

1. Semua Mata Kuliah (MK) pada semester genap 2017/2018 di Program Studi Biologi FMIPA UNSRAT diambil dengan menggunakan Purposive Sampling. Kode MK dapat dilihat pada tabel 1 .

Tabel 1. Mata kuliah

\begin{tabular}{cc}
\hline Nomor & Mata Kuliah \\
\hline 1 & MK1 \\
2 & MK2 \\
3 & MK3 \\
$\vdots$ & $\vdots$ \\
35 & MK35 \\
\hline
\end{tabular}

2. Dari mata kuliah yang telah dipilih tersebut, kemudian diambil sampel mahasiswa dengan menggunakan Simple Random Sampling yang selanjutnya akan diwawancarai dalam bentuk pengisian kusioner penilaian mahasiswa terhadap kinerja dosen dalam proses pembelajaran. Populasi Mahasiswa Biologi yang mengambil mata kuliah pada Semester Genap 2017/2018 disajikan pada tabel 2.

Tabel 2. Populasi Mahasiswa

\begin{tabular}{lclc} 
Kode & Jumlah & Kode & Jumlah \\
MK & Populasi & MK & Populasi \\
\hline MK1 & 13 & MK19 & 38 \\
MK2 & 10 & MK20 & 49 \\
MK3 & 54 & MK21 & 55 \\
MK4 & 38 & MK22 & 2 \\
MK5 & 38 & MK23 & 6 \\
MK6 & 38 & MK24 & 38 \\
MK7 & 58 & MK25 & 40 \\
MK8 & 38 & MK26 & 17 \\
MK9 & 52 & MK27 & 18 \\
MK10 & 8 & MK28 & 20 \\
MK11 & 9 & MK29 & 12 \\
MK12 & 39 & MK30 & 10 \\
MK13 & 1 & MK31 & 8 \\
MK14 & 12 & MK32 & 38 \\
MK15 & 6 & MK33 & 40 \\
MK16 & 7 & MK34 & 40 \\
MK17 & 29 & MK35 & 41 \\
MK18 & 2 & & \\
\hline
\end{tabular}




\section{Peubah Penelitian}

Peubah-peubah yang diamati adalah peubah penentu mutu pelayanan yang terdiri dari Kehandalan, Daya Tanggap, Jaminan, Empati, dan Bukti Langsung.

Peubah-peubah yang diamati adalah tersaji pada Tabel 3-7.

Tabel 3. Peubah Kehandalan (Kedisiplinan) (X1)

\begin{tabular}{cl}
\hline Peubah & \multicolumn{1}{c}{ Definisi } \\
\hline X1a & Kehadiran Dosen \\
X1b & Disiplin Waktu Datang Dosen \\
X1c & Disiplin Waktu Selesai Mengajar \\
& Dosen \\
X1d & $\begin{array}{l}\text { Dosen tidak memperkenankan masuk } \\
\text { kelas (terlambat }>\text { 30menit) }\end{array}$ \\
\hline
\end{tabular}

Tabel 4. Peubah Daya Tanggap (X2)

\begin{tabular}{cl}
\hline Peubah & \multicolumn{1}{c}{ Definisi } \\
\hline X2a & Kesediaan membantu kesulitan \\
X2b & Pemahaman mahasiswa \\
X2c & Pemberian kesempatan bertanya informasi tentang silabus \\
X2d & Pemberian informasi tentang \\
& deskripsi singkat materi \\
X2e & Pemberian informasi tentang hak \\
X2f & dan kewajiban mahasiswa \\
X2g & Pemberian tugas \\
X2h & Pemberian tugas makalah/presentasi soal ujian yang \\
& mencakup seluruh materi \\
X2i & Pemberian ujian tengah semester \\
& atau ujian akhir semester \\
\hline
\end{tabular}

Tabel 5. Peubah Jaminan (Penguasaan Materi) (X3)

\begin{tabular}{cl}
\hline Peubah & \multicolumn{1}{c}{ Definisi } \\
\hline X3a & $\begin{array}{l}\text { Mampu menjelaskan materi dengan } \\
\text { mudah }\end{array}$ \\
X3b & $\begin{array}{l}\text { Pemberian teori disertai contoh } \\
\text { praktis }\end{array}$ \\
X3c & $\begin{array}{l}\text { tugas yang diberi mampu } \\
\text { membantu pemahaman mahasiswa }\end{array}$ \\
X3d & $\begin{array}{l}\text { Makalah/presentasi mampu } \\
\text { membantu pemahaman mahasiswa }\end{array}$ \\
X3e & $\begin{array}{l}\text { Mengajar sesuai silabus dan jadwal } \\
\text { mingguan }\end{array}$ \\
X3f & Mengajar sesuai keahlian \\
\hline
\end{tabular}

Tabel 6. Peubah Empati (X4)

\begin{tabular}{cl}
\hline Peubah & \multicolumn{1}{c}{ Definisi } \\
\hline X4a & Pemberian pujian \\
X4b & Pemberian teguran \\
X4c & Pemberian kesempatan untuk \\
& memperbaiki nilai (remedial) \\
\hline
\end{tabular}

Tabel 7. Peubah Bukti Langsung (X5)

\begin{tabular}{cl}
\hline Peubah & \multicolumn{1}{c}{ Definisi } \\
\hline X5a & Referensi yang digunakan \\
X5b & Penilaian dan komentar tugas \\
X5c & Komentar makalah/presentasi \\
X5d & Pemanfaatan alat bantu ajar \\
\hline
\end{tabular}

\section{Analisis Data}

Metode analisis yang dilakukan dalam penelitian ini ada 2 tahap. Tahapan analisis yang dilakukan adalah sebagai berikut:

1. Data asal dianalisis dengan statistika deskriptif untuk mengetahui gambaran data secara umum menggunakan software pengolah angka. Dalam hal ini faktor penentu mutu pelayanan yaitu kehandalan, daya tanggap, jaminan, empati, dan bukti langsung serta objek pengamatan.

2. Melakukan analisis biplot dengan langkah-langkah sebagai berikut:

- Pemasukan data (matriks data $X$ )

- Standarisasi matriks $X$

- Penguraian matriks $X$ yang telah distandarisasi dengan $S V D$

- Penghitungan matriks $H=A L$ dan $G=U L$

- Plot matriks $G$ dan $H$ secara tumpang tindih

Analisis Biplot dilakukan dengan menggunakan aplikasi $R$-3.5.2 for windows (32 Bit).

\section{HASIL DAN PEMBAHASAN}

Gambar 1, terlihat bahwa bahwa kedekatan antar objek ditunjukkan oleh DS28, DS15, DS11, DS25, DS12, DS18, DS16 karena jarak ketujuh objek yang berdekatan. Hal ini menunjukan bahwa karakteristik ketujuh objek tersebut relatif sama. Sama halnya dengan DS14 dan DS27, DS2 dan DS23, serta DS4 dan DS22. Begitu juga dengan DS26, DS30, DS31, DS13, DS8, DS7 dan DS6 serta DS24, DS17 dan DS1. 


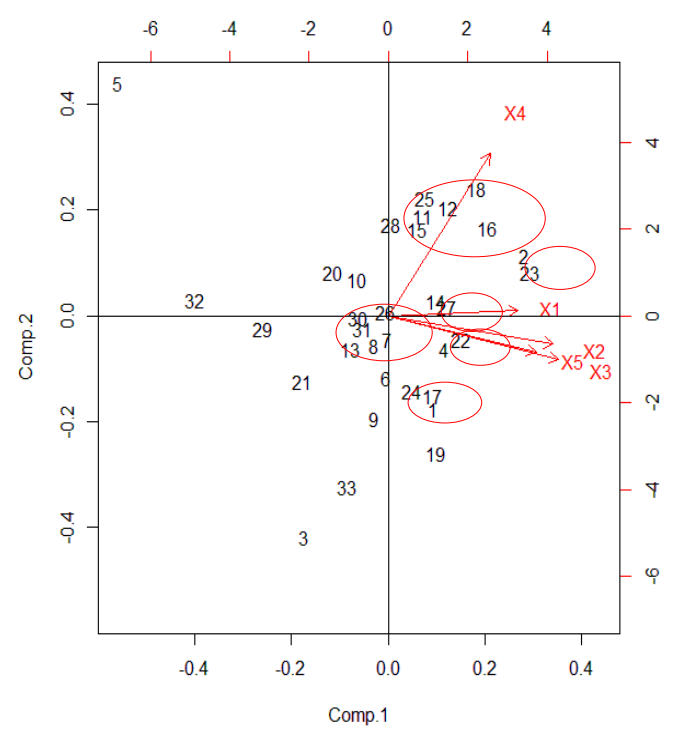

Gambar 1. Biplot 5 peubah (5 faktor penentu mutu pelayanan) dan objek pengamatan

Keragaman yang bisa diterangkan oleh komponen 1 adalah sebesar 63,28\%, sedangkan komponen 2 sebesar 15,36\% sehingga total keragamannya adalah $78,64 \%$. Hal ini berarti bahwa peubah $X 1, X 2, X 3, X 4$, dan $X 5$ membangun pada komponen 1 . Keragaman yang besar terjadi pada peubah Empati (X4) dan peubah Jaminan (X3) karena memiliki vektor yang panjang. Hal ini menunjukkan bahwa dosen-dosen di PS Biologi FMIPA Unsrat sangat beragam dalam hal faktor empati dan bukti langsung. Sedangkan keragaman kecil terjadi pada peubah kehandalan $(X 1)$, karena memiliki vektor yang lebih pendek.

Korelasi positif sempurna terjadi pada peubah jaminan $(X 3)$ dan peubah bukti langsung (X5) karena kedua peubah tersebut memiliki arah yang asma dan membentuk sudut lancip yang sangat kecil. Hal ini berarti bahwa semakin besar jaminan yang mencakup kegiatan belajar mengajar, maka semakin besar bukti langsung yang dimiliki objek.

Pada biplot terlihat bahwa DS14, DS27 dan DS23 memiliki mutu pelayanan dalam hal kehandalan $(X 1)$, karena vektor dari peubah tersebut searah dengan objek DS14, DS27 dan DS23. Selain itu juga dapat dilihat bahwa, DS22 dan DS4 memiliki mutu pelayanan dalam hal jaminan (X3) dan bukti langsung (X5). Kelompok DS15, DS11, DS25, DS12, DS18 dan DS16 juga memiliki mutu pelayanan dalam hal empati $(X 4)$.
DS22 yang memiliki mutu pelayanan dalam hal daya tanggap $(X 2)$.

Tingkat keakuratan biplot dalam menerangkan keragaman matriks data asal yang diperoleh adalah $\rho=0,853$, dari akar ciri terbesar pertama 2,46250427 dan terbesar kedua 0,84171557. Hal ini menunjukkan bahwa keragaman yang dapat diterangkan biplot adalah sebesar 85,30\% dari keragaman data yang sebenarnya. Dengan kata lain interpretasi biplot yang dihasilkan mampu menerangkan dengan baik hubungan antara faktor penentu mutu pelayanan dan objek pengamatan.

\section{KESIMPULAN DAN SARAN}

\section{Kesimpulan}

Dosen yang memiliki nilai rata-rata tertinggi pada faktor kehandalan adalah DS28. Dosen yang memiliki nilai rata-rata tertinggi pada faktor daya tanggap adalah DS2. Dosen yang memiliki nilai rata-rata tertinggi pada faktor empati adalah DS18.

DS23 memiliki nilai rata-rata tertinggi pada faktor jaminan dan bukti langsung. Objekobjek yang dikategorikan memiliki karakteristik mutu pelayanan yang relatif sama yaitu DS14 dan DS27, DS2 dan DS23, DS4 dan DS22, kelompok DS28, DS15, DS11, DS25, DS12, DS18, DS16, kelompok DS26, DS30, DS31, DS13, DS8, DS7 dan DS6 serta kelompok DS24, DS17 dan DS1. Keragaman yang terbesar terjadi pada faktor empati dan jaminan. Sedangkan keragaman kecil dimiliki oleh faktor kehandalan. DS22 memiliki mutu pelayanan dalam hal daya tanggap (X2). DS4 dan DS22 memiliki mutu pelayanan dalam hal jaminan $(X 3)$ dan bukti langsung (X5). Kelompok DS15, DS11, DS25, DS12, DS18 dan DS16, memiliki mutu dalam hal empati $(X 4)$. DS5 dan DS32 memiliki karakteristik mutu yang tidak baik, karena memiliki jarak yang berjauhan dengan semua objek dan faktorfaktor penentu mutu pelayanan.

\section{Saran}

Program Studi Biologi FMIPA UNSRAT perlu meningkatkan mutu pelayanan jasa pendidikan, terutama pada faktor empati dan jaminan agar PS Biologi 
mampu untuk meningkatkan pelayanan yang lebih baik, efektif dan efisien.

\section{DAFTAR PUSTAKA}

Everit, B. 1978. Graphical Techniques for Multivariate Data. Heinermann Educational Books.

Gobel. T. D. Hatidja dan H.A.H Komalig. 2013. Karakteristik Kualitas Pengajar Berdasarkan Faktor Mutu Pelayanan di Jurusan Matematika FMIPA UNSRAT Menggunakan Analisis Biplot. Jurnal MIPA Unsrat Online 2(1) 29-33.

Jollife, I. T. 1986. Principle Component Analysis. Springer Verlag, New York.

Kotler, P. 2000. Marketing Management. Prentice hall,Inc. New Jersey.

Liputo, D., D. Hatidja dan Y.A.R. Langi. 2014. Analisis Korepondensi Terhadap Karakteristik Kinerja Dosen Berdasarkan Faktor Penentu Mutu Pelayanan Di Jurusan Matematika Fmipa Universitas Sam Ratulangi. Jurnal De Cartesian 3(1): 50-57. DOI: $10.35799 /$ dc.3.1.2014.3807

Mattjik, A.A., M. Sumertajaya, H. Wijayanto, Indahwati, A. Kurnia, B. Sartono. 2004. Modul Teori Pelatihan Analisis Multivariat. Departemen Statistika FMIPA IPB. Bogor.

Moenir, A. S. 2008. Manajemen Pelayanan Umum di Indonesia. Bumi Aksara. Jakarta

Pangemanan, Y., D. Hatidja dan H.A.H. Komalig. 2014. Persepsi Alumni Matematika Terhadap Layanan dan Fasilitas Akademik Serta Penelitian dan Pengabdian kepada Masyarakat Di Program Studi Matematika FMIPA UNSRAT dengan Menggunakan Analisis Korespondensi. Jurnal De Cartesian 3(1): 36-42.

DOI: $10.35799 / \mathrm{dc} .3 .1 .2014 .3807$

Peraturan Pemerintah (PP) nomor 19 tahun 2005 tentang Standar Nasional Pendidikan.
Purwanto, Ch., D. Hatidja dan Paendong. 2015. Pemetaan SMA/SMK Di Kabupaten Minahasa Tenggara Berdasarkan Empat Indikator Standar Nasional Pendidikan Dengan Menggunakan Analisis Biplot. Jurnal De Cartesian 4(1): 35-41.

DOI: $10.35799 / \mathrm{dc} .3 .1 .2014 .3807$

Rencher, A.R. 2002. Methods Of Multivariate Analysis Second Edition. John Wiley and Sons, Inc, New York.

Tumilaar, P., D. Hatidja dan J.D. Prang. 2014. Analisis Korespondensi Terhadap Persepsi Alumni Program Studi Matematika FMIPA Universitas Sam Ratulangi Mengenai Kurikulum Dan Proses Pembelajaran. Jurnal De Cartesian 3(1): 23-29.

DOI: $10.35799 / \mathrm{dc} .3 .1 .2014 .3803$ 